\title{
Saúde coletiva: um campo plural de saberes e práticas
}

BAGRICHEVSKY, M.; ESTEVÃO, A. (Org.)

Saúde coletiva: dialogando sobre interfaces temáticas.

Ilhéus, BA: Editus, 2015. 542p.

I Alan Camargo Silva I

${ }^{1}$ Universidade Federal do Rio de Janeiro. Rio de Janeiro-RJ, Brasil (alan10@zipmail.com.br).

Recebido em: 26/04/2015

Aprovado em: 25/09/2015

DOI: http://dx.doi.org/10.1590/S0103-73312016000200019

Marcos Bagrichevsky e Adriana Estevão são docentes da Universidade Federal do Espírito Santo, atuam no Programa de Pós-Graduação em Educação Física e coordenam o Núcleo Interdisciplinar de Estudos e Pesquisas sobre Saúde, Cultura e Sociedade dessa mesma instituição. As trajetórias acadêmico-profissionais dos organizadores são atravessadas essencialmente pelos referenciais das Ciências Sociais/Humanas em Saúde.

As experiências dos organizadores em coletâneas voltadas ao corpo na Educação Física (BAGRICHEVSKY; PALMA; ESTEVÃO, 2003; BAGRICHEVSKY et al., 2006; BAGRICHEVSKY; ESTEVÃO; PALMA, 2007) e suas argumentações sobre a aproximação desta área com a Saúde Coletiva (BAGRICHEVSKY; ESTEVÃO, 2008; BAGRICHEVSKY; ESTEVÃO; PALMA, 2008) indicam que a presente obra pode ser considerada uma referência importante para diversos campos de conhecimento. O título, "Saúde coletiva: dialogando sobre interfaces temáticas", sugere que a leitura deste livro é indispensável na medida em que a Saúde Coletiva se constitui justamente por um campo plural de saberes e práticas.

Após a apresentação do livro, os 15 textos são assinados por colaboradores comprometidos com reflexões instigantes e relevantes sobre diversos temas atuais sobre corpo e saúde-doença. A pluralidade teórico-metodológica e a densidade argumentativa dos autores tornam a leitura rica e fundamental para compreender 
o pensar, o sentir e o agir de todos aqueles que estão envolvidos direta ou indiretamente com o Sistema Único de Saúde (SUS), a saber.

O texto que introduz a coletânea, "Nasce o corpo! Um transcurso heterogêneo", é elaborado por Fernando Yonezawa e Hélio Rebello Cardoso Júnior. Os autores debatem sobre a desnaturalização do corpo e questionam a visão fragmentada do mesmo no contexto ocidental. O capítulo discute as concepções de corpo das sociedades "primitivas" ou "selvagens" e faz pensar em outros modos contemporâneos de conceber a corporeidade, como suas potências virtuais que podem criar um problema ético: o que pode um corpo?

O capítulo seguinte, intitulado "Experimentação e encontro intercessor: produzindo pistas para a educação física na saúde mental”, foi desenvolvido por José Geraldo Damico e Luiz Fernando Bilibio. Os autores propõem um estranhamento e uma problematização sobre a especificidade da intervenção da Educação Física e da atividade física no SUS, em especial, no contexto da saúde mental. A racionalidade técnico-científica da biomedicina, que permeia os saberes e as práticas dos profissionais de saúde, como na Educação Física, é substancialmente questionada no texto. Sugere-se um cuidado terapêutico baseado no exercício de alteridade face àquele em sofrimento psíquico.

No terceiro texto, "Uma relação entre conceito de saúde, normatividade e biopolítica", por meio das reflexões de Georges Canguilhem e Michel Foucault, Monica Roza discute a noção de saúde pautada no referencial biomédico. A autora destaca a importância de compreender o sentido e o valor dados à vida para além de um tipo ideal natural positivista que ainda permeia o campo sanitário a favor de uma questionável definição de saúde de "perfeito bem-estar psicossocial".

"A estetização da saúde", de autoria de Francisco Romão Ferreira, é o quarto texto do livro. O capítulo esclarece como o atributo estético pode se tornar sinônimo de saúde, realidade esta, muitas vezes, legitimada pelos profissionais do campo e por discursos técnico-científicos. O avanço das biotecnologias e a expansão da mercadorização das transformações corporais fazem partem de novas problemáticas relevantes para a Saúde Pública. O autor faz pensar nos elementos éticos envolvidos no processo de medicalização do cuidado do corpo.

O quinto capítulo, "Cuidar e curar para governar: as campanhas de saúde na escola”, assinado por Iolanda Santos, discute como o Programa Nacional de Saúde Escolar pode contribuir para a normalização e controle universal dos 
corpos infantis. Baseada primordialmente nas reflexões de Michel Foucault, a autora explora documentos oficiais que propõem como a escola deve intervir com seus alunos, professores e familiares acerca da prevenção da cegueira e da surdez. Questiona-se a relação higienista entre discurso pedagógico e terapêutico em formar e docilizar corpos em busca de comportamentos ditos saudáveis.

Posteriormente, "Sobre a promoção da saúde na escola: uma contribuição da história”, Fernanda Paiva analisa os sentidos construídos nas theses médicas defendidas na Faculdade de Medicina no Rio de Janeiro durante o século XIX. A autora questiona a medicalização do social incutida nas especificidades médicas da época e suas relações com os primórdios da intervenção da Educação Física e com a educação do corpo no processo de escolarização.

No capítulo seguinte, "Desigualdades sociais, promoção da saúde e práticas corporais: por uma ressignificação contextualizada”, Marcos Bagrichevsky, Adriana Estevão e Paulo Roberto Vasconcellos-Silva abordam como a proposta do exercitar-se pode se institucionalizar no setor saúde. Com base na Declaração de Alma-Alta em 1978, os autores analisam duas iniciativas públicas voltadas às práticas corporais/atividades físicas do Espírito Santo à luz das discussões sobre desigualdades/iniquidades sociais em saúde tão propaladas pela Reforma Sanitária brasileira.

O oitavo capítulo, desenvolvido por Marcos Santos Ferreira e Luis David Castiel, "Promoção da saúde, empowerment e o discurso da vida ativa", aponta como tais noções podem ser utilizadas de maneiras diferentes. Isto é, interpretadas tanto por meio de discursos dominantes ou conservadores com enfoque individual e comportamental quanto a partir de abordagens críticas ou progressistas preocupadas com determinantes coletivos das condições de vida e de saúde da sociedade. A partir da análise de um programa que propóe uma "vida ativa”, o Agita São Paulo, os autores discutem a multiplicidade de abordagens de empowerment e a dubiedade da noção de promoção da saúde que, por vezes, se distanciam das propostas do SUS.

Escrito por Luciana Caliman, o nono capítulo do livro, "Quando os estilos de vida se tornam estilos de risco", esclarece os limites e as potencialidades do biopoder de Michel Foucault para analisar a subjetividade no campo da saúde contemporânea. Em termos gerais, a autora problematiza os usos das obras de Michel Foucault no sentido de apreender a gestão do risco. 
No décimo capítulo, "Estratégias de governamentalidade no âmbito da promoção da saúde: o controle do peso corporal como estilo de vida saudável”, de Adriane Ramiro, há uma discussão em torno do aumento da preocupação com a obesidade nos últimos tempos. A autora discute criticamente as formas como as políticas e as práticas voltadas ao controle da gordura corporal vêm sendo tratadas no âmbito da promoção da saúde.

"Conselhos privados, escolhas e novas formas de exclusão social: a obesidade como metáfora contemporânea", elaborado por Ivan Marcelo Gomes, Alexandre Vaz e Selvino José Assmann, é o título do décimo primeiro capítulo. Fundamentado em Zygmunt Bauman, há reflexōes acerca do "ser obeso" que, de certo modo, indicam como a sociedade contemporânea lida ou se posiciona face à liberdade, às políticas do corpo e à exclusão social.

Mais à frente, o livro conta com o texto de Monica Carvalho, intitulado "Obesidade e pobreza na imprensa: epidemiologia de uma questão social". Por meio da análise do jornal Folha de São Paulo entre 1996 a 2005, o trabalho objetiva apreender os discursos midiáticos referentes ao aumento de peso em classes sociais menos favorecidas. A autora explora o impacto das pesquisas epidemiológicas sobre o par obesidade/pobreza em um cenário político de disputas discursivas no que diz respeito ao cuidado em saúde.

Em seguida, Ednalva Neves é autora do capítulo intitulado "Sob a égide da epidemiologia do risco: legitimidade e controle através da normalização social", onde aborda as relações entre cultura e ciência no âmbito da associação entre risco e saúde, levando em consideração a pluralidade de práticas sanitárias. Ao longo do capítulo, questiona-se a hegemonia da racionalidade epidemiológica perante outras formas interpretativas de conceber a noção de risco.

No penúltimo texto da obra, "Epidemiologia e senso comum: a construção compartilhada do conhecimento em saúde”, José Wellington Araújo destaca a importância e a necessidade do criticismo histórico acerca da prática epidemiológica para além do seu sentido utilitário. $\mathrm{O}$ autor propõe um processo dialógico entre uma epidemiologia contra-hegemônica e os ideais emancipatórios do SUS.

E, fechando a obra, Miriam Graciano é autora do último texto da coletânea: "Pensamento e prática em epidemiologia e saúde pública". O capítulo traz uma discussão sobre a dimensão ética do saber epidemiológico a partir da conexão entre o biológico e o social nos planos conceitual e prático. $\mathrm{O}$ texto permite refletir sobre os limites e nas potencialidades epistemológicas contemporâneas 
entre epidemiologia e saúde pública, análise esta tão importante para evitar o foco da categoria "causalidade" restrita aos aspectos metodológicos.

Em síntese, durante a leitura do livro, é possível apreender e perceber a sensibilidade crítica e a robustez teórica dos textos em questionar alguns problemas contemporâneos que impactam diretamente nos modos de viver dos sujeitos. A obra consegue abranger inúmeras discussóes calcadas em aspectos históricos, filosóficos, socioeconômicos e culturais que circundam a sociedade atual para além do referencial biológico. Por exemplo, o exacerbado valor dado à racionalidade científica e às biotecnologias, tornando sujeitos corpos-objetos de intervenção. Os processos de medicalização da vida, que tentam reger os comportamentos dos sujeitos face ao complexo processo saúde-doença. A presença capitalista que, a todo instante, reforça a responsabilidade individual pela saúde em detrimento do dever do Estado em reduzir as iniquidades sociais.

Obras como esta, de Marcos Bagrichevsky e Adriana Estevão, que consegue reunir diferentes "olhares" sobre o corpo e a saúde-doença, estimulam a revisão e a atualização dos marcos teórico-metodológicos da própria Saúde Coletiva. Revisitar clássicos objetos de estudo e explorar novas tendências de investigação e de reflexão do campo da saúde são apenas alguns potenciais convidativos para a leitura do livro Saúde coletiva: dialogando sobre interfaces temáticas.

Recomenda-se, portanto, sua leitura àqueles que atuam criticamente no espaço acadêmico e/ou profissional da Saúde Coletiva. A obra faz repensar nos modos tradicionais de gestão em saúde, enriquece os saberes envolvidos na produção de conhecimento e amplia as práticas de intervenção sanitária, na medida em que o corpo e a saúde-doença são pensados e discutidos de acordo com os princípios e diretrizes do SUS.

\section{Referências}

BAGRICHEVSKY, M.; ESTEVÃO, A. Perspectivas para a formação profissional em Educação Física: o SUS como horizonte de atuação. Arquivos em Movimento, Rio de Janeiro, v. 4, n. 1, p. 128-143, jan./jun. 2008.

BAGRICHEVSKY, M.; ESTEVÃO, A.; PALMA, A. (Org.). A saúde em debate na Educação Física. v. 3, Ilhéus, BA: Editus, 2007. 294p.

. La Educación Física y su inserción en el campo de la salud colectiva en Brasil: en búsqueda de un diálogo crítico sobre interfaces, pertenencias y sentidos. Physis, Rio de Janeiro, v. 18, n. 1, p. 123-142, 2008. 
BAGRICHEVSKY, M.; PALMA, A.; ESTEVÃO, A. (Org.). A saúde em debate na Educação Física. Blumenau, SC: Edibes, 2003. 191p.

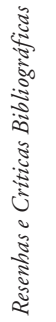

BAGRICHEVSKY, M. et al. (Org.). A saúde em debate na Educação Física. v. 2, Blumenau, SC: Nova Letra, 2006. 240p. 